\title{
Logistic Principles Application for Managing the Extraction and Transportation of Solid Minerals
}

\author{
Alexey Tyurin ${ }^{1 *}$ \\ ${ }^{1}$ T.F. Gorbachev Kuzbass State Technical University, 650000, 28 Vesennyaya St., Kemerovo, Russia
}

\begin{abstract}
Reducing the cost of resources in solid mineral extraction is an urgent task. For its solution the article proposes logistic approach use to management of mining company all resources, including extraction processes, transport, mineral handling and storage. The account of the uneven operation of mining, transport units and complexes for processing and loading coal into railroad cars allows you to identify the shortcomings in the work of the entire enterprise and reduce resources use at the planned production level. In the article the mining planning model taking into account the dynamics of the production, transport stations and export coal to consumers rail transport on example of Krasnoyarsk region Nazarovo JSC «Razrez Sereul'skiy». Rolling planning methods use and data aggregation allows you to split the planning horizon (month) on equal periods and to use of dynamic programming method for building mining optimal production programme for the month. Coal mining production program definition technique will help align the work of all enterprise units, to optimize resources of all areas, to establish a flexible relationship between manufacturer and consumer, to take into account the irregularity of rail transport.
\end{abstract}

\section{Introduction}

Logistic approach application to management of material and accompanying information, financial and service flow has been successfully implemented in various of economy sectors [1-2], including in the area of solid minerals mining [3-6].

Using the basic logistic principles (rationality, integrity, consistency, hierarchy, and integration) in the field of mining allows you to link all production, transport and other service processes in a single system [7-9].

The use of resource-saving technologies not only during mining, but also in its dissemination to the end customer allows you to get a superior competitive advantage - the reduction in the price of the finished product and potential market expansion, profitability of the enterprise.

To achieve this, must reduce all logistics costs in the chain «producer-consumer» due to the review of the production, transport and storage processes consistency in the field of mining solid minerals [10-12].

\footnotetext{
* Corresponding author: alexturin07@rambler.ru
} 


\section{Materials and methods}

The object of the study was JSC «Razrez Sereul'skiy», Nazarovo of Krasnoyarsk region. The coal mine is carried out extraction of brown coal. The main consumer of the coal mine is Novosibirsk CHPP-3 of JSC «SIBEKO». JSC «Razrez Sereul'skiy» includes the following production areas:

- production area, which produces overburden and mining of the existing excavator fleet;

- technological transport area, which transports overburden on the inside, the outside blade (the fleet of BelAZ dump trucks), transportation of coal mined at the warehouse "Central" (the fleet of BelAZ dump trucks);

- motor transport area, which carries out transportation of coal from the warehouse «Central» to warehouse «Transshipment» Volvo dump trucks;

- technological complex of coal loading, which provides the receipt and storage of coal at the warehouse «Transshipment», and performs the loading of coal into railroad cars to the consumer.

Coal mining is carried out by excavators HITACHI-470, Liebherr 984 loading of coal into dump trucks BelAZ 7555D, as well as attracting overburden dump trucks BelAZ 7540, 75473 , hauling to the warehouse «Central». Warehouse organization is allowed:

-eliminate downtime for transportation of coal due to climatic conditions;

-exclude access to transport third-party organizations and consumers working in the mining sector (loading coal in the mine), ensuring safety of mining operations;

-remove the hard interaction of production processes, transportation and commercial products shipment, which increases the productivity of mining shovels.

Coal loading at the warehouse «Central» is carried out by a front loader DRESSTA 534C. The transportation of coal from the warehouse «Central» to Nazarovo station railway deadlock on warehouse «Transshipment» is carried out by dump trucks VOLVO BCM-51.1 with a transportation distance of $39.5 \mathrm{~km}$. the General scheme of extraction and transportation of coal to consumers is presented in figure 1 .

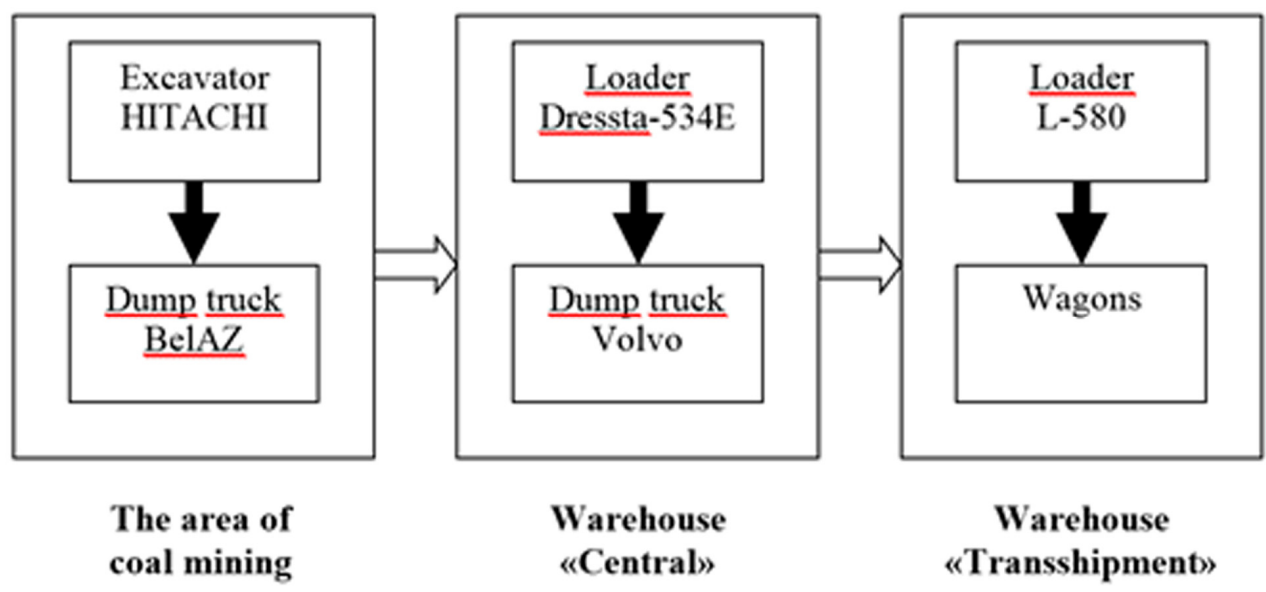

Fig. 1. General diagram of the extraction and transportation of coal.

The uneven supply of wagons for loading to the warehouse «Transshipment» (figure 2) affects the irregularity of the excavators work (figure 3) and trucks at the coal mining area and warehouse «Central». All this leads to equipment downtime, reduced productivity of production area and, as a consequence, to higher costs in the chain «producer-consumer» 
and the prices of finished products. Thus, the resources of the enterprise are used inefficiently.

The elimination of these disadvantages is possible through the logistic approach use to management of all coal mine processes and accounting of all costs for production, handling and transportation of coal to the consumer. For this, rolling planning method use is proposed. Planning period - a month, which is divided into 10 periods of 3-4 days in the period. The aggregation of time intervals will take into account the uneven supply of wagons (environmental conditions) and to adapt the coal mine operation (conditions of the internal environment) for the new parameters of the environment.

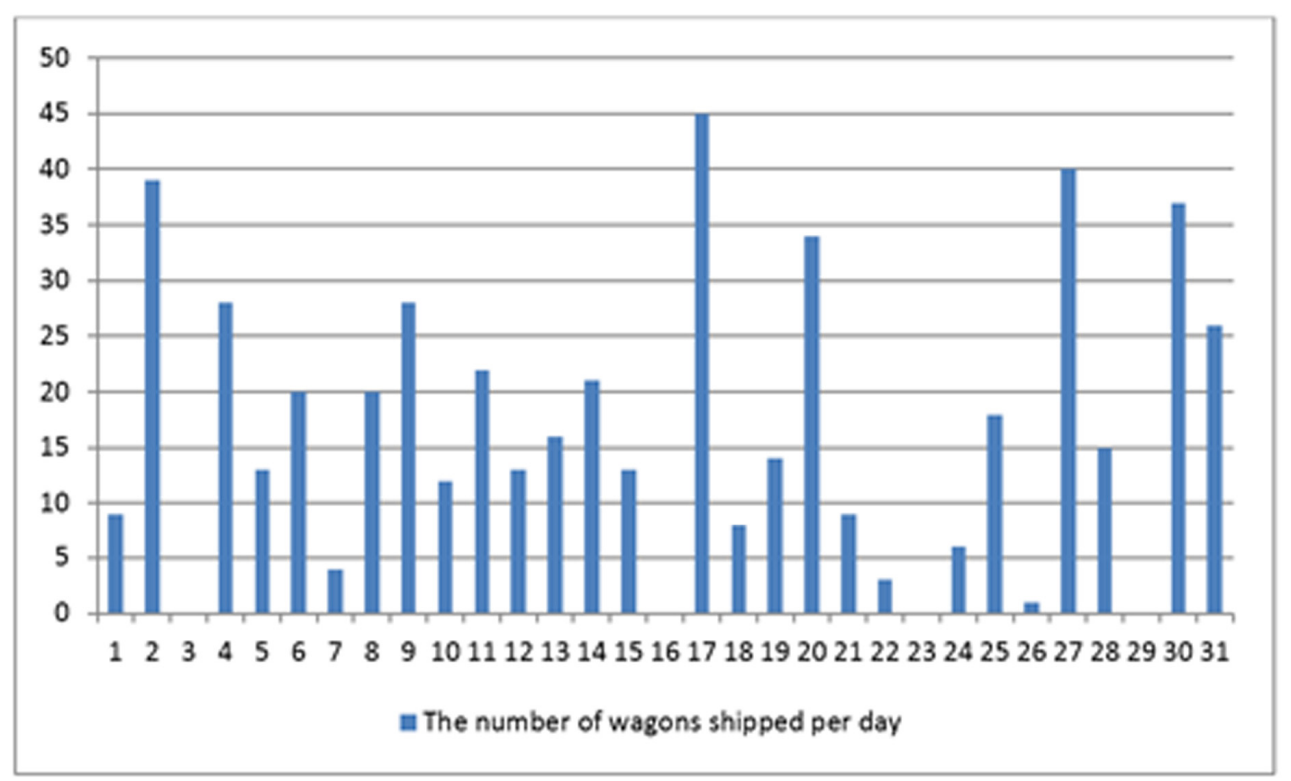

Fig. 2. Uneven loading of wagons in March 2017.

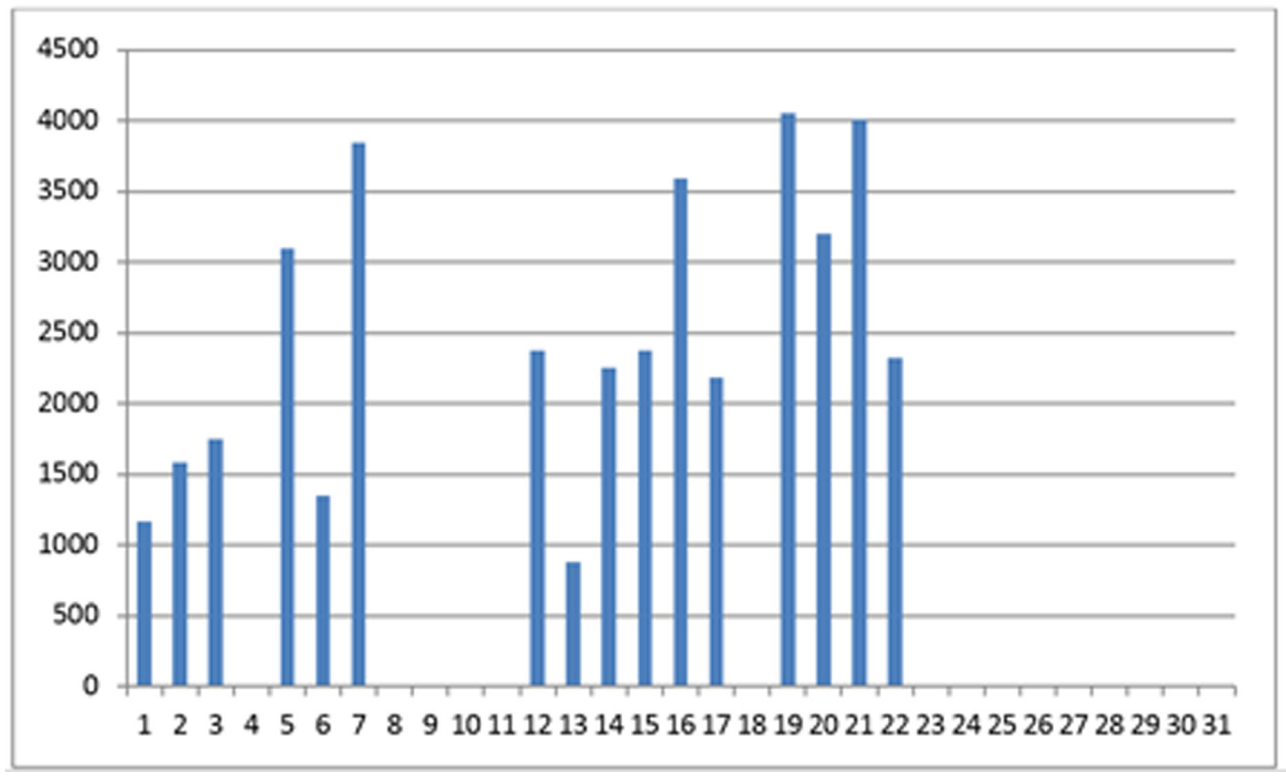

Fig. 3. Uneven production of coal in tons for March 2017. 
The optimal production plan problem for March 2017 based on the production scheduling based on the analysis of product demand (wagons loading).

Consider the mathematical formulation of the problem. Denote by rk the demand, and using $\mathrm{zk}$ - the required capacity of the coal mine in $\mathrm{k}$-th period, $\mathrm{k}=1, \mathrm{~m}$, where $\mathrm{m}$ is the number of orders received during the month. In this case $\mathrm{z} 0=\mathrm{c}$ is some fixed initial level of production. For timely execution of orders requires that demand is always met, i.e., $\mathrm{zk} \geq \mathrm{rk}$, $\mathrm{k}=1, \mathrm{~m}$.

The problem is to minimize the sum of two functions damages (increased costs towards the optimal costs) and penalties [13]:

a) $g_{k}\left(z_{k}-r_{k}\right)$ - damages and penalties in the k-th period, due to the fact that production exceeds demand and excess stocks appear;

б) $h_{k}\left(z_{k}-z_{k-1}\right)$ - damages and penalties in the $\mathrm{k}$-th period, caused by the unevenness of the production program by months.

Thus, the first function $\left(g_{k}\right)$ determines the losses from overproduction of products, the second $\left(h_{k}\right)$ - losses associated with inventories or services.

Then the objective function can be written in the form:

$$
L\left(z_{1}, z_{2}, \ldots, z_{m}\right)=\sum_{k=1}^{m}\left[g_{k}\left(z_{k}-r_{k}\right)+h_{k}\left(z_{k}-z_{k-1}\right)\right] \rightarrow \min
$$

under the constraints

$$
\mathrm{z}_{\mathrm{k}} \geq \mathrm{r}_{\mathrm{k}}, \mathrm{k}=1, \mathrm{~m}
$$

This problem can be solved by dynamic programming. Denote by $f_{k}(c)$ total cost at the optimal production program for a month, if before the end of the planning period is $\mathrm{k}$ periods. Then, the estimated solution can be obtained using the following recurrence relations:

$$
f_{k}(c)=\min _{z_{k} \geq r_{k}}\left\{g_{k}\left(z_{k}-r_{k}\right)+h_{k}\left(z_{k}-c\right)+f_{k+1}\left(z_{k}\right)\right\}, \quad k=\overline{1, m},
$$

where

$$
\begin{array}{ll}
r_{k-1} \leq c \leq \max _{k} r_{k}, & k=\overline{1, m} \\
r_{k} \leq z_{k} \leq \max _{k} r_{k}, & k=\overline{1, m}
\end{array}
$$

Initial conditions: $\mathrm{f}_{\mathrm{m}+1}(\mathrm{c})=0$ и $\mathrm{r} 0=0$.

\section{Results and discussion}

Using a mathematical model (1-5) will calculate the planned performance indicators of the open pit given the intensity of export of coal to consumers.

The planning horizon (month) is divided into $\mathrm{m}=10$ periods.

Count the total number of loaded wagons for periods (it will demand) (table 1).

Table 1. Dynamics of demand for March 2017

\begin{tabular}{|l|c|c|c|c|c|c|c|c|c|c|}
\hline $\mathbf{k}$ & 1 & 2 & 3 & 4 & 5 & 6 & 7 & 8 & 9 & 10 \\
\hline $\mathbf{r}_{\mathbf{k}}$ & 48 & 61 & 52 & 47 & 50 & 53 & 57 & 9 & 59 & 78 \\
\hline
\end{tabular}


Given the cost of loading and transportation of coal parameter $g_{k}$ in (1) will be 8925,74 RUB/wagon. The $h_{k}$ option will affect the cost of unproductive downtime of excavators and dump trucks in the case of the uneven production during the month. Hence $h_{k}$ in (1) will be 1789,46 RUB/wagon.

Using (3) with (4-5) we get the optimal production programme of coal production (table 2 ), which leads to extraction and transportation costs minimization of coal to consumers.

Table 2. Optimal production program of March 2017

\begin{tabular}{|c|c|c|c|c|c|c|c|c|c|c|}
\hline $\mathrm{k}$ & 1 & 2 & 3 & 4 & 5 & 6 & 7 & 8 & 9 & 10 \\
\hline $\mathrm{r}_{\mathrm{k}}$ & 48 & 61 & 52 & 47 & 50 & 53 & 57 & 9 & 59 & 78 \\
\hline $\mathrm{Z}_{\mathrm{k}}$ & 61 & 61 & 60 & 60 & 60 & 60 & 60 & 60 & 60 & 78 \\
\hline
\end{tabular}

In table 2 the production program presented in the wagons. Moving on from the wagons to the ton and breaking periods per day, and will receive the calculated optimal production programme of coal production for March 2017 (figure 4).

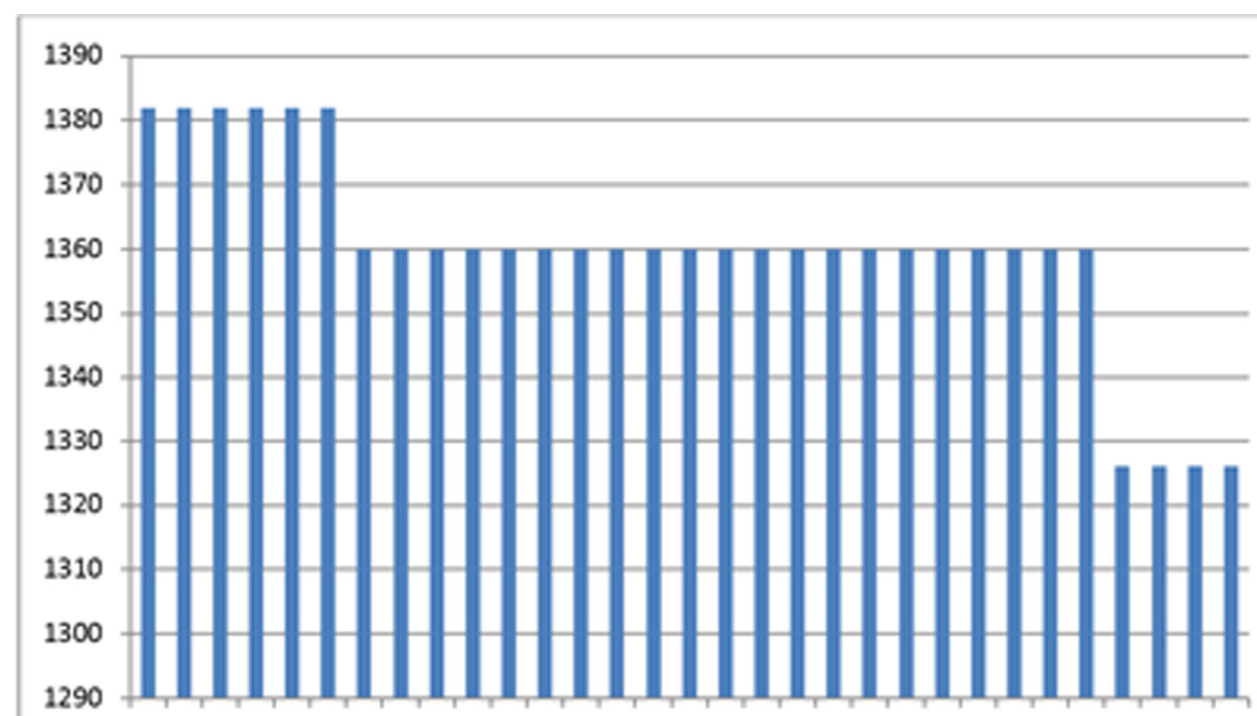

$123 \quad 4 \quad 5 \quad 6 \quad 7 \quad 8910111213141516171819202122232425262728293031$

Fig. 4. Estimated optimal programme of coal production in tons for March 2017.

The results show that the level of coal production is expected to decline from the beginning of the month to the end. The use of such production policies will allow to align the work of production sites, transport and warehouses with a decrease in financial resources, as reflected in table 3 .

Table 3. Analysis of actual and optimal costs on the production - warehouse «Transshipment»

\begin{tabular}{|l|l|c|c|c|}
\hline No. & \multicolumn{1}{|c|}{ Area } & \multicolumn{2}{|c|}{ Expenses for March 2017, RUB } & \multirow{2}{*}{ Deviation, RUB } \\
\cline { 3 - 4 } & \multicolumn{2}{|c|}{ actual } & optimal & 282259.31 \\
\hline 1. & $\begin{array}{l}\text { Area of coal production - } \\
\text { warehouse "Central" } \\
\text { including: }\end{array}$ & 2206229.64 & 1923970.33 & 179891.51 \\
\hline 1.1. & $\begin{array}{l}\text { Loading of coal by excavator } \\
\text { HITACHI }\end{array}$ & 1037332.18 & 857430.67 & 102367.80 \\
\hline 1.2. & $\begin{array}{l}\text { Transportation of coal by } \\
\text { haul trucks BelAZ 7555D }\end{array}$ & 1168907.46 & 1066539.66 & 1021612.97 \\
\hline 2. & Warehouse «Central»- & 6666652.41 & 5645039.44 & \\
\hline
\end{tabular}




\begin{tabular}{|l|l|c|c|c|}
\hline & $\begin{array}{l}\text { warehouse «Trans- } \\
\text { shipment», including: }\end{array}$ & & & \\
\hline 2.1. & $\begin{array}{l}\text { Coal loading loader } \\
\text { DRESSTA -534E }\end{array}$ & 659223.36 & 527512.59 & 131710.77 \\
\hline 2.2 & $\begin{array}{l}\text { Coal transportation dump } \\
\text { trucks VOLVO BCM-51.1 }\end{array}$ & 6007429.05 & 5117526.86 & 889902.20 \\
\hline 3. & $\begin{array}{l}\text { Area of coal production - } \\
\text { warehouse «Trans-shipment» }\end{array}$ & 8872882.05 & 7569009.78 & 1303872.28 \\
\hline
\end{tabular}

\section{Conclusions}

Coal mining production program definition technique will help align the work of all enterprise units, to optimize resources of all areas, to establish a flexible relationship between manufacturer and consumer, to take into account the irregularity of rail transport. Application of rolling planning methods (grouping by periods) to allow you to release unnecessary enterprise resources and redirect them to the needed objects or to realize in the market.

\section{References}

1. A. Yu. Tyurin, KuzSTU Bul. 3, 106 (2005)

2. E. V. Khrapova, J. Rus. Entr., 11:2, 61 (2010)

3. A. A. Tverdov, A. V. Zhura, S. B. Nikishichev, Coal, 8:1037, 86 (2012)

4. R. Chicoisne, D. Espinoza, M. Goycoolea, E. Moreno, E. Rubio, Oper. Res. 60:3, 517 (2012)

5. C. Cullenbine, K.Wood, A. Newman, Optimization Letters, 88:3,365 (2011)

6. D. Espinoza, M. Goycoolea, E. Moreno, A. Newman, Annals of Operations Research, 206, 93 (2013)

7. A. Yu. Tyurin, KuzSTU Bul. 1, 40 (2000)

8. Ju. D. Pristupa, GIAB, 4, 369 (2012)

9. Ju. D. Pristupa, KuzSTU Bul. 1, 91 (2012)

10. H. Askari-Nasab, K. Awuah-Offei, H. Eivazy, Int. J. Min. Miner. Eng. 2, 185 (2010)

11. E. Klotz, A. M. Newman, Surveys in Operations Research and Management Science, 18:12, 18 (2013)

12. A. Newman, E. Rubio, R. Caro, A. Weintraub, K. A. Eurek, Interfaces, 40:3,222 (2010)

13. A. Y. Tyurin, KuzSTU Bul. 1, 94 (2004) 